\title{
GSI Treatment Preserves Protein Synthesis in C2C12 Myotubes
}

\author{
Joshua R. Huot ${ }^{1,2}{ }^{\oplus}$, Brian Thompson ${ }^{1}$, Charlotte McMullen ${ }^{1}$, Joseph S. Marino ${ }^{1}$ and Susan T. Arthur ${ }^{1, *}$ \\ 1 Laboratory of Systems Physiology, Department of Kinesiology, University of North Carolina at Charlotte, \\ Charlotte, NC 28223, USA; jrhuot@iu.edu (J.R.H.); brianthompson072@gmail.com (B.T.); \\ charlottemc27@gmail.com (C.M.); joseph.marino@uncc.edu (J.S.M.) \\ 2 Department of Surgery, Indiana University School of Medicine, Indianapolis, IN 46202, USA \\ * Correspondence: sarthur8@uncc.edu; Tel.: +1-(704)-687-0856
}

Citation: Huot, J.R.; Thompson, B.; McMullen, C.; Marino, J.S.; Arthur, S.T. GSI Treatment Preserves Protein Synthesis in C2C12 Myotubes. Cells 2021, 10, 1786. https://doi.org/ $10.3390 /$ cells10071786

Academic Editors: Jean Christopher Chamcheu, Claudia Bürger and Shile Huang

Received: 27 May 2021

Accepted: 13 July 2021

Published: 15 July 2021

Publisher's Note: MDPI stays neutral with regard to jurisdictional claims in published maps and institutional affiliations.

Copyright: (c) 2021 by the authors. Licensee MDPI, Basel, Switzerland. This article is an open access article distributed under the terms and conditions of the Creative Commons Attribution (CC BY) license (https:// creativecommons.org/licenses/by/ $4.0 /)$.

\begin{abstract}
It has been demonstrated that inhibiting Notch signaling through $\gamma$-secretase inhibitor (GSI) treatment increases myogenesis, AKT/mTOR signaling, and muscle protein synthesis (MPS) in $\mathrm{C} 2 \mathrm{C} 12$ myotubes. The purpose of this study was to determine if GSI-mediated effects on myogenesis and MPS are dependent on AKT/mTOR signaling. C2C12 cells were assessed for indices of myotube formation, anabolic signaling, and MPS following GSI treatment in combination with rapamycin and API-1, inhibitors of mTOR and AKT, respectively. GSI treatment increased several indices of myotube fusion and MPS in C2C12 myotubes. GSI-mediated effects on myotube formation and fusion were completely negated by treatment with rapamycin and API-1. Meanwhile, GSI treatment was able to rescue MPS in C2C12 myotubes exposed to rapamycin or rapamycin combined with API-1. Examination of protein expression revealed that GSI treatment was able to rescue pGSK3 $\beta$ Ser9 despite AKT inhibition by API-1. These findings demonstrate that GSI treatment is able to rescue MPS independent of AKT/mTOR signaling, possibly via GSK3 $\beta$ modulation.
\end{abstract}

Keywords: muscle protein synthesis; GSI; mTOR; AKT

\section{Introduction}

Skeletal muscle wasting is a debilitating result of aging and several disease states, which drastically reduces functional capacity and quality of life [1-3]. Loss of skeletal muscle mass can be attributed to increased protein catabolism, impaired muscle regeneration (i.e., myogenesis), and/or reductions in muscle protein synthesis (MPS) $[1,4,5]$. The protein kinase B (AKT)/mechanistic target of rapamycin (mTOR) cascade is pivotal for several processes within skeletal muscle including survival, autophagy, differentiation, and MPS [6,7]. Interestingly, emerging evidence has identified mTOR as a primary antagonist of lifespan, revealing that administration of rapamycin (a potent inhibitor of mTOR) can increase lifespan, improve aging, and combat age-related disease development [8-13]. However, reduced mTOR signaling in skeletal muscle diminishes myogenic potential, and reduces anabolic potential of exercise and nutrients [14,15]. This poses an interesting dilemma for skeletal muscle researchers, in particular when seeking to maintain muscle mass in diseased and aged populations.

Another pathway strongly implicated in skeletal muscle health and disease is Notch signaling [1]. Notch is activated when one of its four receptors (Notch1-4) binds to one of several Notch ligands (Delta-like protein (DLL)1, DLL3, DLL4, Jagged1, Jagged2), which initiates successive metalloprotease and $\gamma$-secretase cleavages [1]. Aside from its developmental regulation, Notch signaling dictates the myogenic response following injury $[16,17]$. Similar to mTOR, dysfunctional Notch signaling may also occur in atrophic skeletal muscle, blunting skeletal muscle regeneration [16,18-20]. Moreover, aberrant Notch signaling has been implicated in the development of insulin resistance and cachexia [21-23]. Meanwhile, targeting the $\gamma$-secretase cleavage via $\gamma$-secretase inhibitors (GSIs), a commonly used method to chemically inhibit Notch signaling, has demonstrated that reduced Notch 
signaling increases myotube formation and muscle growth [22,24,25]. Altogether, these findings make Notch an interesting target to potentially combat muscle atrophy in aging and other skeletal muscle wasting diseases.

Reducing mTOR activity can promote healthy aging, yet at the same time blunts the anabolic potential of skeletal muscle. Thus, identifying and targeting signaling pathways that modulate MPS independent of mTOR may help to sustain skeletal muscle mass in the aging population. One example of this is AKT, which can mediate MPS via glycogen synthase kinase 3 beta (GSK3 $\beta$ ) independently of mTOR [26-28]. Interestingly, our lab recently demonstrated that Notch inhibition via GSI treatment elevated MPS in C2C12 myoblasts and myotubes by modulating the phosphatase and tensin homolog (PTEN)/AKT/mTOR signaling cascade [25]. However, it is not known if this mechanism is reliant on mTOR or if GSIs mediate MPS in an AKT-dependent manner.

Thus, in the present study we sought to investigate whether the beneficial effects of GSIs on myotube size and MPS were dependent on AKT/mTOR. Here, we again demonstrate that GSI treatment increases differentiation and MPS in C2C12 myotubes. Inhibition of AKT and mTOR ablated GSI-induced differentiation in C2C12 cells. However, GSI treatment preserved MPS rates in combination with AKT and mTOR inhibition, suggesting that the use of GSIs may be able to augment MPS independent of AKT/mTOR.

\section{Materials and Methods}

\subsection{Cell Culture}

For all in vitro experiments, C2C12 skeletal muscle myoblasts (ATCC p3-p8) were cultured in Dulbecco's Modified Eagles Medium (DMEM), supplemented with $10 \%$ fetal bovine serum, $10 \%$ horse serum (HS), and $1 \%$ penicillin/streptomycin (P/S), as performed previously [25]. In particular, we previously demonstrated that $\gamma$-secretase inhibitor (GSI-4 $\mu \mathrm{M}$ : L-685,458; Millipore Sigma- dimethyl sulfoxide (DMSO)) treatment on the onset of $\mathrm{C} 2 \mathrm{C} 12$ differentiation increases myotube fusion and AKT/mTOR signaling [25]. Thus, to examine if GSI-mediated effects on myotube fusion were dependent on AKT $/ \mathrm{mTOR}$, we exposed C2C12s at the onset of differentiation to $4 \mu \mathrm{M}$ GSI in combination with $100 \mathrm{nM}$ rapamycin (RAP; 13346; Cayman Chemicals in DMSO) or $10 \mu \mathrm{M}$ 4-Amino-5,8-dihydro-5oxo-8-b-D-ribofuranosyl-pyrido[2,3-d]pyrimidine-6-carboxamide (API-1; SML1342; Millipore Sigma in DMSO), established inhibitors of mTOR and AKT, respectively [29-31]. Specifically, for the differentiating $\mathrm{C} 2 \mathrm{C} 12$ experiments, myoblasts were grown to full confluence, switched to differentiation media (DM: DMEM supplemented with $2 \%$ HS and $1 \% \mathrm{P} / \mathrm{S}$ ) and treated every $12 \mathrm{~h}$ for $96 \mathrm{~h}$ in one of the following conditions: (1) GSI, RAP, GSI + RAP, or control (Con: DMSO). (2) GSI, API-1, GSI + API-1, or Con. Myotubes from these experiments were analyzed for indices of fusion and area as outlined below. In addition to demonstrating that GSI treatment enhances $\mathrm{C} 2 \mathrm{C} 12$ differentiation, we also previously reported that differentiated myotubes exposed to GSI for $24 \mathrm{~h}$ was sufficient to increase MPS [25]. Thus, to determine if the GSI-mediated effects on MPS in differentiated myotubes were reliant on AKT/mTOR signaling, $\mathrm{C} 2 \mathrm{C} 12 \mathrm{~s}$ were allowed to differentiate for $72 \mathrm{~h}$ and were then treated twice (every $12 \mathrm{~h}$ ) for the next $24 \mathrm{~h}$ under one of the following conditions: (1) GSI, RAP, GSI + RAP, or Con; (2) GSI, API-1, GSI + API-1, or Con; (3) GSI, $\mathrm{RAP}+\mathrm{API}-1, \mathrm{GSI}+\mathrm{RAP}+\mathrm{API}-1$, or Con. Myotubes from these experiments were analyzed for protein expression, protein synthesis, and myotube diameter, as detailed below.

\subsection{Myosin Heavy Chain Staining}

Following $96 \mathrm{~h}$ of differentiation, myotubes were stained with myosin heavy chain (MHC) and assessed for properties of fusion, area, and diameter, as performed previously [25,32]. Briefly, myotubes were fixed with $70 \%$ acetone $/ 30 \%$ methanol, serially washed with PBS, blocked for $1 \mathrm{~h}$, and incubated overnight in MHC (MF-20, 1:100; Developmental Studies Hybridoma Bank, Iowa City, IA, USA). Myotubes were subsequently PBS-washed, incubated with an anti-mouse secondary antibody (1:200) and 4',6-Diamidino2-Phenylindole, Dihydrochloride (DAPI 1:1000) for $1 \mathrm{~h}$, and mounted with Vectashield. 


\subsection{Myotube Fusion, Area, and Diameter}

Stained myotubes were captured at $20 \times$ for indices of fusion and area on an Olympus iX inverted microscope, as performed previously [25]. Following image acquisition, 2 blinded individuals quantified indices of myotube fusion, including myotube number, total nuclei, and fused nuclei using ImageJ. Myotube area was determined from the same images used to calculate fusion index using Adobe Photoshop, as previously described [33]. Briefly, three randomly selected images from each experimental group (Con, GSI, RAP, GSI + RAP or Con, GSI, API-1, GSI + API-1) were used to set accepted tones for MHC (red) and DAPI (blue). The set color range was then subsequently applied to all images in order to obtain measures for total myotube area, area per myotube, and myotube area per fused nuclei. For myotube size, ImageJ software was used to measure the narrowest diameter along the myotube (400 myotubes per condition) [32,34].

\subsection{Protein Synthesis}

For assessment of protein synthesis, myotubes were treated with $1 \mu \mathrm{M}$ puromycin (P-1033, A.G. Scientific, San Diego, CA, USA) $30 \mathrm{~min}$ prior to cell collection, as previously described $[25,35,36]$. Puromycin incorporation was subsequently analyzed via western blot, as detailed below.

\subsection{Western Blot}

To extract protein from $\mathrm{C} 2 \mathrm{C} 12$ myotubes, well surfaces were washed two times with cold PBS, mechanically lysed in chilled Radioimmunoprecipitation assay (RIPA) buffer (sc-24948; Santa Cruz Biotechnology, Dallas, TX, USA) containing 1\% Triton-x, 2\% SDS and protease cocktail inhibitors, as performed previously [25], and centrifuged for $20 \mathrm{~min}$ at $20,000 \times g\left(4{ }^{\circ} \mathrm{C}\right)$. Following centrifugation $\left(20,000 \times g, 20 \mathrm{~min}, 4^{\circ} \mathrm{C}\right)$, the supernatant was saved and assessed for protein concentration by the BCA protein assay method (23225; ThermoFisher, Waltham, MA, USA). Samples $(20 \mu \mathrm{g})$ were loaded and electrophoresed on a 4-12\% Bis-Tris gel (3450125; Bio-Rad, Hercules, CA, USA) at $125 \mathrm{~V}$ for $2 \mathrm{~h}$, as performed previously [25]. Proteins were then transferred (Towbin Buffer; $10 \%$ methanol) onto a $0.22 \mu \mathrm{M}$ Polyvinylidene difluoride (PVDF) membrane for $1 \mathrm{~h}$ at $100 \mathrm{~V}$. Membranes were washed in Tris-buffered saline (TBS), blocked for $1 \mathrm{~h}$ in Odyssey blocking buffer (1:1 TBS), and incubated overnight in primary antibodies. Following primary antibody incubation, membranes were serially washed in TBST (TBS: $0.1 \%$ Tween 20) and incubated in secondary antibodies (1:10,000 in TBST) for $1 \mathrm{~h}$. Membranes were again serially washed in TBST, and proteins were then visualized and quantified using the Odyssey ${ }^{\circledR}$ Licor CLx System. Antibodies used were as follows: pAKT Thr308 (\#13038; 1:500), pAKT Ser473 (\#4060; 1:500), AKT (\#2920; 1:1000), pmTOR Ser2448 (\#5536; 1:500), mTOR (\#4517, 1:1000), p4EBP1 Thr37/46 (\#2855; 1:500), 4EBP1 (\#9644; 1:1000), pp70S6K Thr389 (\#9234; 1:500), p70S6K (\#2708; 1:1000), peEF2 Thr56 (\#2331; 1:500), eEF2 (\#2332; 1:1000), pGSK3 $\beta$ Ser9 (\#8566; 1:500), GSK3 $\beta$ (\#5676; 1:1000), and ABC (\#8814; 1:1000) from Cell Signaling; Puromycin (\#MABE343; 1:5000) from EMD Millipore; and $\beta$-Actin (\#A2228; 1:10,000) from Sigma Aldrich, St. Louis, MI, USA.

\subsection{Statistical Analysis}

One-way analysis of variance (ANOVA) tests were performed to determine differences between experimental groups (1) GSI, RAP, GSI + RAP, or Con. 2) GSI, API-1, GSI + API-1, or Con. 3) GSI, RAP + API-1, GSI + RAP + API-1, or Con). Post-hoc comparisons were accomplished via a Tukey's test, with statistical significance set apriori at $p \leq 0.05$. All statistical analyses and graphs were made using Graphpad Prism 7.03 (GraphPad, San Diego, CA, USA). All data are presented as means \pm SD. 


\section{Results}

\subsection{Rapamycin Ablates GSI-Mediated Elevations in Myotube Formation}

Since our work previously demonstrated that Notch inhibition via GSI treatment was sufficient to increase myotube formation as well as mTOR signaling, we wanted to determine whether GSI-mediated effects on myogenesis were dependent on mTOR [25]. Thus, we treated differentiating C2C12 myotubes with GSI and the commonly used mTOR inhibitor, rapamycin, for $96 \mathrm{~h}$. Similar to our previous reported results, GSI treatment significantly increased several indices of myotube formation compared to all groups, including fused nuclei per field, nuclei per myotube per field, and fusion index per field (Figure 1). GSI treatment also resulted in significantly reduced non-fused nuclei compared to all other groups (Figure 1). Interestingly, RAP significantly reduced fused nuclei, nuclei per myotube, and fusion index compared to Con, but did not differ from GSI + RAP in any of these measures, suggesting that GSI-mediated increases in fusion are dependent on mTOR (Figure 1). Moreover, both RAP and GSI + RAP had significantly elevated non-fused nuclei compared to Con, while also increasing total nuclei per field compared to Con and GSI, yet did not differ from each other (Figure 1). The myotube number was also significantly reduced in RAP and GSI + RAP compared to both Con and GSI (Figure 1). With respect to area measures, GSI treatment increased total myotube area, area per myotube, and myotube area per fused nuclei (Figure 1). Meanwhile, RAP and GSI + RAP both reduced myotube area, area per myotube, and myotube area per fused nuclei compared to Con, further suggesting that GSI-mediated increases in myotube formation are dependent on mTOR (Figure 1).

A)
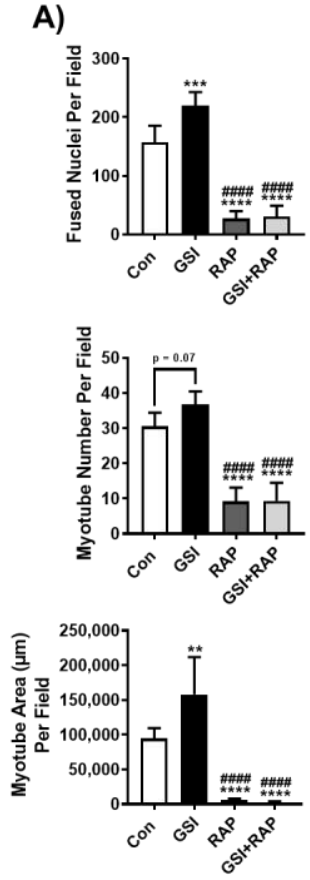
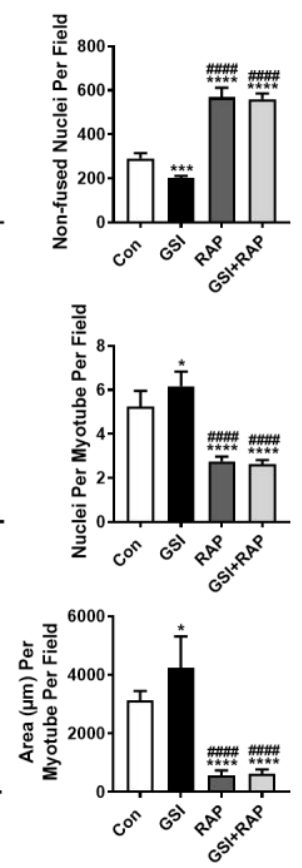
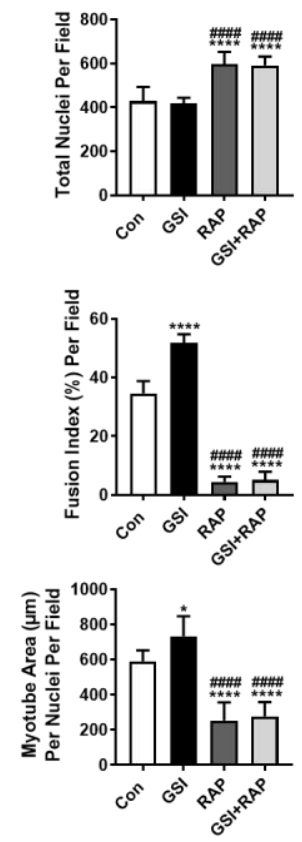

B)

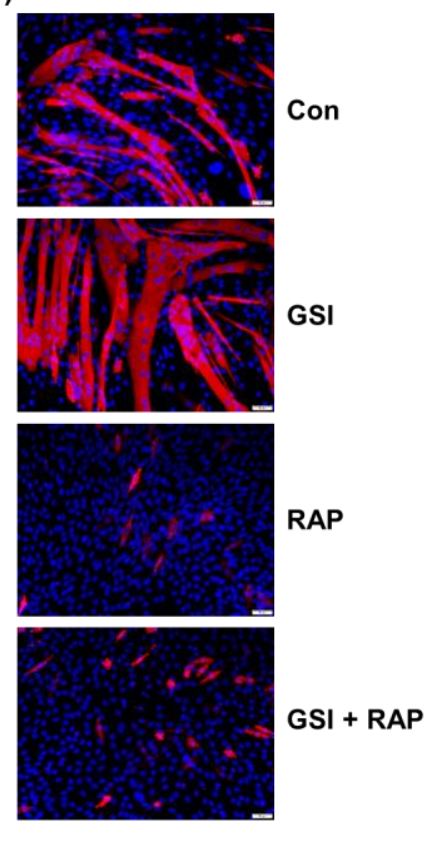

Figure 1. Rapamycin ablates GSI-mediated elevations in myotube formation. (A) Indices of myotube fusion and area. Graph order, top left to right: Fused nuclei per field, Non-fused nuclei per field, and Total nuclei per field. Graph order, middle left to right: Myotube number per field, Nuclei per myotube per field, Fusion index per field. Graph order, bottom left to right: Myotube area $(\mu \mathrm{m})$ per field, Area $(\mu \mathrm{m})$ per myotube per field, Myotube area $(\mu \mathrm{m})$ per nuclei per field. (B) Representative image of 96-h myotubes co-stained with myosin heavy chain (MHC:red) and DAPI:blue. Images were taken at $20 \times$ magnification and the scale bar $=50 \mu \mathrm{m}$. At the onset of differentiation $\mathrm{C} 2 \mathrm{C} 12$ cells were treated every $12 \mathrm{~h}$ with either control (Con), $4 \mu \mathrm{M} \gamma$-secretase inhibitor (GSI), $100 \mathrm{nM}$ rapamycin (RAP), or GSI + RAP co-treatment. All data were analyzed using a one-way ANOVA followed by Tukey's multiple comparison test. ${ }^{*} p<0.05,{ }^{* *} p<0.01,{ }^{* * *} p<0.001$, ${ }^{* * * *} p<0.0001$ vs. Con; \#\#\#\# $p<0.0001$ vs. GSI ( $n=3$ experiments). Data are mean \pm SD. 


\subsection{GSI Treatment Preserves Protein Synthesis in the Presence of Rapamycin}

We previously demonstrated that GSI treatment increased MPS in differentiating and differentiated C2C12 myotubes [25]. As the present data demonstrated that the use of rapamycin ablated GSI-augmented fusion, we wanted to determine whether the effects of GSI on MPS were also reliant on mTOR. To do this we differentiated C2C12 myotubes for $72 \mathrm{~h}$ and then exposed them to GSI and RAP for $24 \mathrm{~h}$. Confirming our published work, GSI treatment increased protein synthesis compared to all other groups, while RAP exhibited reduced protein synthesis compared to Con (Figure 2A). Interestingly, GSI treatment protected protein synthesis rates and myotube size in the presence of RAP (Figure 2A and Figure S1). In addition, in line with our prior work, GSI treatment increased phosphorylated (p)-mTOR at Ser2448 compared to all other groups, while p-mTOR was reduced compared to Con in both RAP and GSI + RAP treated myotubes, suggesting that GSI preservation of MPS is not dependent on mTOR (Figure 2B). Moreover, despite increasing p-mTOR, GSI treatment did not exert effects directly downstream of mTOR (p-4EBP1, p-p70S6K, p-eEF2), which is comparable to our prior findings (Figure 2C-E) [25]. Meanwhile, RAP and GSI + RAP did not differ in any downstream target of mTOR, showing reduced 4EBP1, reduced p-p70S6K, and increased p-eEF2 (Figure 2B-D). These results suggest that GSI treatment may protect MPS levels in the presence of rapamycin and thus may modulate MPS in mechanisms other than mTOR.

A)

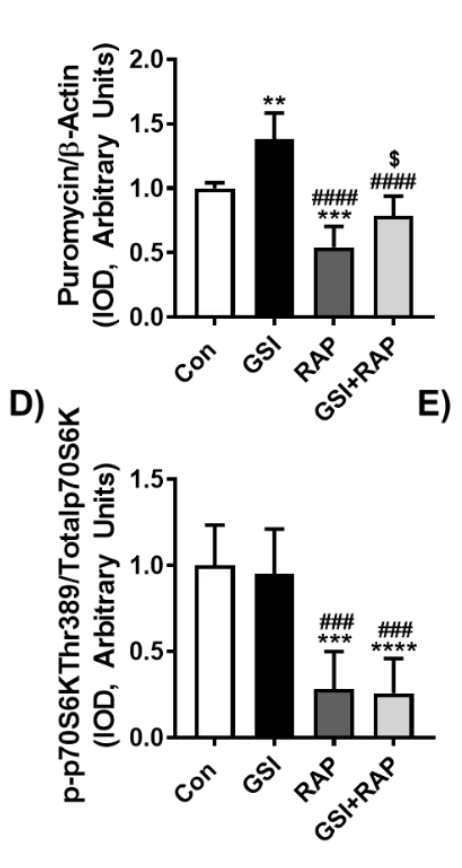

B)
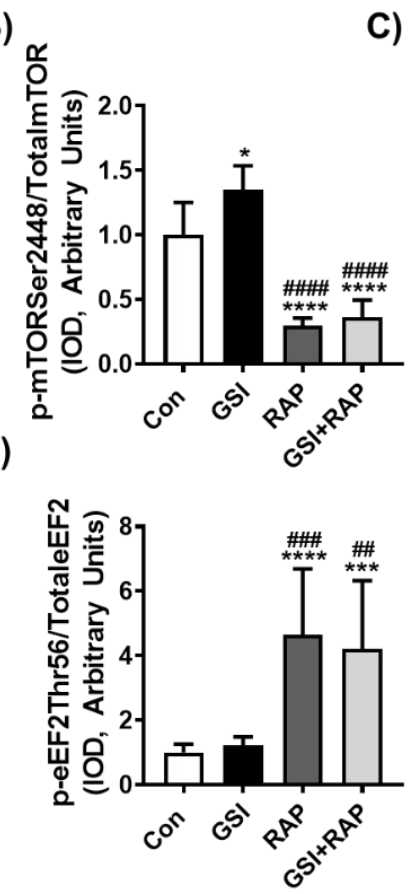

C)
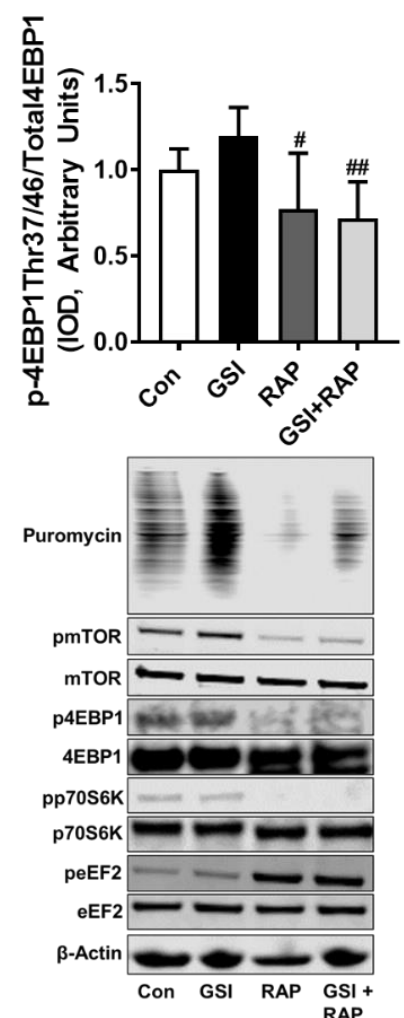

Figure 2. GSI treatment rescues protein synthesis in the presence of rapamycin. Representative western blotting and quantification (expressed as fold change vs. control (Con) for (A) Puromycin/ $\beta$-Actin (B) Phospho (p)-mTOR Ser2448/Total mTOR; (C) p-4EBP1 Thr37/46/Total 4EBP1; (D) p70S6K Thr389/Total p70S6K; and (E) p-eEF2 Thr56/Total eEF2. Next, $72 \mathrm{~h}$ post-differentiation, C2C12 cells were treated every $12 \mathrm{~h}$ with either Con, $4 \mu \mathrm{M} \gamma$-secretase inhibitor (GSI), $100 \mathrm{nM}$ rapamycin (RAP), or GSI + RAP co-treatment until $96 \mathrm{~h}$ post-differentiation. Then, $30 \mathrm{~min}$ prior to collection, all cells were treated with $1 \mu \mathrm{M}$ puromycin. All data were analyzed using a one-way ANOVA followed by Tukey's multiple comparison

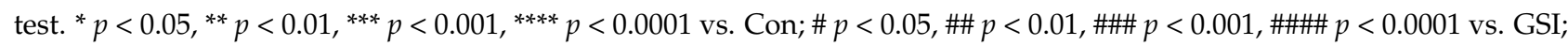
$\$ p<0.05$ vs. $\operatorname{RAP}(n=3$ experiments). Data are mean \pm SD. 


\subsection{API-1 Ablates GSI-Mediated Elevations in Myotube Formation}

To expand upon our prior findings that GSI treatment promotes fusion as well as increased AKT signaling in $\mathrm{C} 2 \mathrm{C} 12 \mathrm{~s}$, we also decided to investigate if AKT was necessary for GSI-mediated effects on myotube formation [25]. To do this we treated differentiating C2C12s with GSI and an AKT inhibitor, API-1. In concert with previous experiments, GSI treatment increased all measured markers of myotube formation and fusion. GSI treatment increased fused nuclei, nuclei per myotube, and fusion index compared to all other groups (Figure 3). API-1 and GSI + API-1 treatment induced lower fused nuclei, nuclei per myotube, and fusion index compared to Con, but did not differ from each other in any parameter (Figure 3). GSI treatment also reduced non-fused nuclei compared to Con; however, there were no differences between the other groups (Con; API-1; GSI + API-1) (Figure 3). The lack of difference in non-fused nuclei between groups is likely due to the significant reduction seen in total nuclei with API-1 and GSI + API-1 treatment (Figure 3). Similar to reductions in total nuclei per field, the myotube number was also reduced in API-1 and GSI + API-1 compared to Con and GSI (Figure 3). Regarding area measures, total myotube area, area per myotube, and myotube area per fused nuclei were increased with GSI treatment compared to all groups (Figure 3). Further suggesting that API-1 treatment ablates myotube formation induced by GSI treatment, API-1 and GSI + API-1 had reduced total myotube area, area per myotube, and myotube area per fused nuclei compared to Con, but did not differ from each other in any parameter (Figure 3).

A)
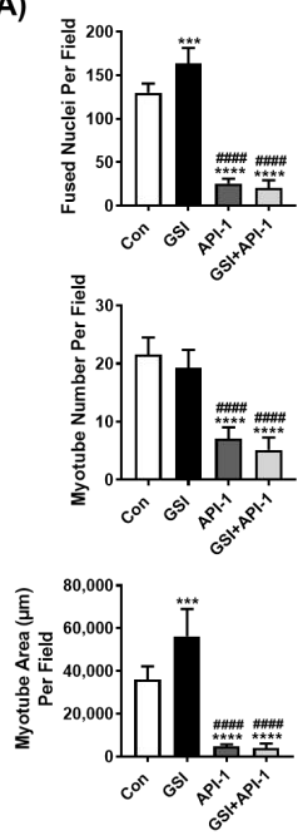
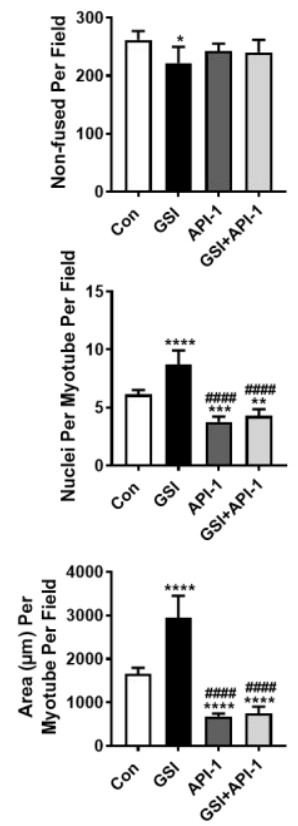
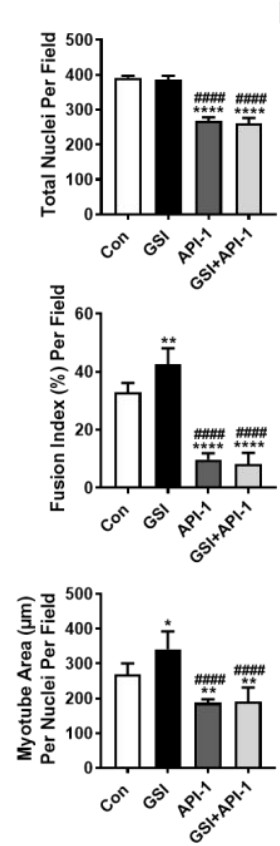

B)

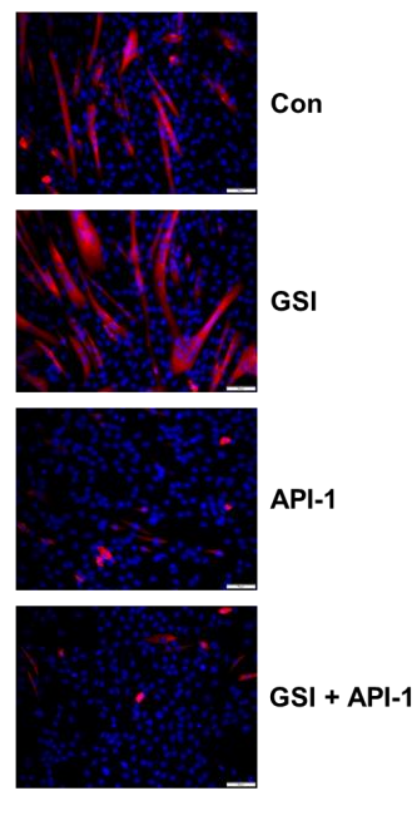

Figure 3. API-1 ablates GSI-mediated elevations in myotube formation. (A) Indices of myotube fusion and area. Graph order, top left to right: Fused nuclei per field, Non-fused nuclei per field, and Total nuclei per field. Graph order, middle left to right: Myotube number per field, Nuclei per myotube per field, Fusion index per field. Graph order, bottom left to right: Myotube area $(\mu \mathrm{m})$ per field, Area $(\mu \mathrm{m})$ per myotube per field, Myotube area $(\mu \mathrm{m})$ per nuclei per field. (B) Representative image of 96-h myotubes co-stained with myosin heavy chain (MHC:red) and DAPI:blue. Images were taken at 20× magnification and the scale bar $=50 \mu \mathrm{m}$. At the onset of differentiation $\mathrm{C} 2 \mathrm{C} 12$ cells were treated every $12 \mathrm{~h}$ with either control (Con), $4 \mu \mathrm{M}$ $\gamma$-secretase inhibitor (GSI), $10 \mu \mathrm{M}$ 4-Amino-5,8-dihydro-5-oxo-8- $\beta$-D-ribofuranosyl-pyrido[2,3-d]pyrimidine-6-carboxamide (API-1), or GSI + API-1 co-treatment. All data were analyzed using a one-way ANOVA followed by Tukey's multiple comparison test. ${ }^{*} p<0.05,{ }^{* *} p<0.01,{ }^{* * *} p<0.001,{ }^{* * *} p<0.0001$ vs. Con; \#\#\#\# $p<0.0001$ vs. GSI $(n=3$ experiments). Data are mean $\pm \mathrm{SD}$. 


\subsection{GSI Treatment Preserves Protein Synthesis in the Presence of API-1 and Rapamycin}

Given our prior findings that GSI-treated myotubes have increased AKT signaling along with increased MPS and our present findings that GSI treatment protected MPS in the presence of rapamycin, we wanted to determine whether GSI-mediated effects on MPS are dependent on AKT (Figure 2) [25]. This was also of interest as AKT can mediate MPS independently of mTOR by way of GSK3 $\beta$ [26-28]. In line with our prior findings, GSI treatment increased MPS and myotube size compared to all groups; however, the use of API-1 was not sufficient to reduce MPS compared to Con (Figure 4A and Figure S2). In addition, MPS with GSI + API-1 was no different than API-1 alone, suggesting that GSI-mediated effects on MPS may be dependent on AKT (Figure 4A). However, despite not reducing MPS, API-1 was sufficient to reduce myotube size, while introduction of GSI in the presence of API-1 preserved the myotube size (Figure S2). Interestingly, though GSI treatment increased phosphorylation of AKT on both Thr308 and Ser473, the use of API-1 was only sufficient to reduce pAKT Ser473 (Figure 4B,C), and GSI + API-1 did not differ from API-1 at either phosphorylation site (Figure 4B,C). Downstream of AKT, GSI treatment significantly elevated pmTORSer2448 compared to all groups (Figure 4D). Intriguingly, and similar to pAKT Thr308, API-1 and GSI + API-1 did not reduce pmTORSer2448 compared to Con, nor were they different from each other, suggesting that GSI treatments elevation of mTOR may be dependent on AKT. In addition, the fact that pmTOR did not reduce with API-1 treatment may also explain the lack of reduction in MPS.

A)

D)

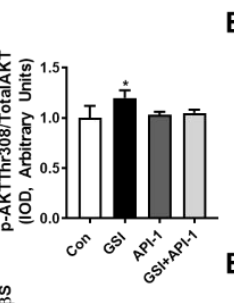

B)

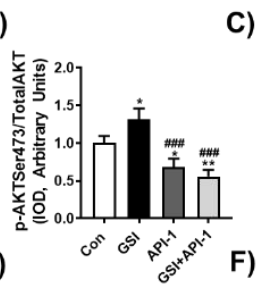

C)
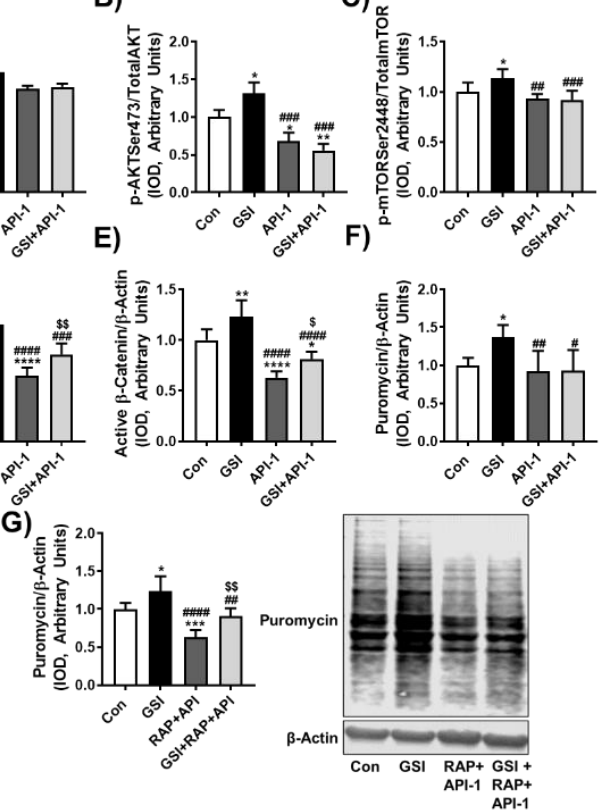

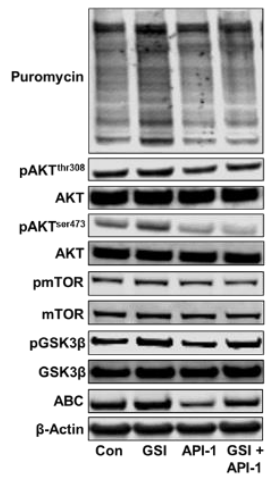

Figure 4. GSI treatment rescues protein synthesis in the presence of API-1 and rapamycin. Representative western blotting and quantification (expressed as fold change vs. control (Con) for (A) Puromycin/ $\beta$-Actin; (B) Phospho (p)-AKT Thr308/Total AKT; (C) p-AKT Ser473/Total AKT; (D) p-mTOR Ser2448/Total mTOR; (E) p-GSK3 $\beta$ Ser9/Total GSK3 $\beta$; (F) Active $\beta$-Catenin/ $\beta$-Actin. Then, $72 \mathrm{~h}$ post-differentiation, $\mathrm{C} 2 \mathrm{C} 12$ cells were treated every $12 \mathrm{~h}$ with either Con, $4 \mu \mathrm{M} \gamma$-secretase inhibitor (GSI), $10 \mu \mathrm{M}$ 4-Amino-5,8-dihydro-5-oxo-8- $\beta$-D-ribofuranosyl-pyrido[2,3-d]pyrimidine-6carboxamide (API-1), or GSI + API-1 co-treatment until $96 \mathrm{~h}$ post-differentiation. All cells were treated with $1 \mu \mathrm{M}$ puromycin $30 \mathrm{~min}$ prior to collection. Representative western blotting and quantification for (G) Puromycin/ $\beta$-Actin. Next, $72 \mathrm{~h}$ post-differentiation, C2C12 cells were treated every $12 \mathrm{~h}$ with either Con, $4 \mu \mathrm{M}$ GSI, $100 \mathrm{nM}$ rapamycin (RAP) + $10 \mu \mathrm{M}$ API-1, or GSI + RAP + API-1 co-treatment until $96 \mathrm{~h}$ post-differentiation. All cells were treated with $1 \mu \mathrm{M}$ puromycin $30 \mathrm{~min}$ prior to collection. All data were analyzed using a one-way ANOVA followed by Tukey's multiple comparison test. 
${ }^{*} p<0.05,{ }^{* *} p<0.01,{ }^{* * *} p<0.001,{ }^{* * * *} p<0.0001$ vs. Con; $\# p<0.05, \# \# p<0.01, \# \# \#<0.001$, \#\#\#\# $p<0.0001$ vs. GSI; $\$ p<0.05, \$ \$ p<0.01$ vs. API-1 (D,E); \$ $p<0.01$ vs. RAP + API-1 (G) $(n=3$ experiments). Data are mean $\pm \mathrm{SD}$.

Since AKT also mediates protein synthesis independently of mTOR by phosphorylating GSK3 $\beta$, we wanted to assess if this signaling was changed with GSI and with API-1 treatments. GSI-treated $\mathrm{C} 2 \mathrm{C} 12 \mathrm{~s}$ demonstrated elevations in pGSK3 $\beta$ Ser9 (Figure 4E), and while API-1 did not cause reductions in mTOR, it did reduce pGSK3 $\beta$ Ser9 compared to Con (Figure 4E). Intriguingly, pGSK3 $\beta$ Ser9 was elevated in GSI + API-1 compared to API-1 and did not differ from Con. Moreover, GSI treatment increased active $\beta$-catenin (ABC) compared to all groups and GSI + API-1 was sufficient to preserve ABC compared to API-1 alone (Figure $4 \mathrm{~F}$ ). The preservation of pGSK3 $\beta$ Ser9 with GSI treatment in combination with API-1 convinced us to observe protein synthesis conditions in which MPS would surely be reduced. Thus, we conducted an additional experiment set utilizing GSI + RAP + API-1. Again, GSI treatment increased MPS compared to all other groups (Figure 4G). Treatment of $\mathrm{C} 2 \mathrm{C} 12 \mathrm{~s}$ with RAP + API-1 significantly reduced MPS and myotube size compared to Con, while the introduction of GSI in the presence of RAP + API-1 preserved both MPS and myotube size (Figure 4G and Figure S3).

\section{Discussion}

Our lab recently demonstrated that Notch inhibition via GSI treatment elevates protein synthesis in C2C12 muscle cells, possibly through modulation of the AKT/mTOR signaling cascade [25]. In the present study, we expand upon our prior findings and demonstrate that GSI treatment may be able to augment MPS independent of AKT/mTOR, as GSI treatment in the presence of $\mathrm{mTOR}$ and AKT inhibition was able to provide protection of protein synthesis in C2C12 myotubes.

One goal of the present study was to determine if the GSI-mediated elevations in myotube formation and growth was dependent on $\mathrm{mTOR}$, as $\mathrm{mTOR}$ is a pivotal regulator of myogenesis [37-39]. Here, we show that GSI treatment significantly elevates a myriad of fusion and hypertrophy indices (fusion index, area/myotube, and myotube area/fused nuclei) in differentiating $\mathrm{C} 2 \mathrm{C} 12$ myotubes and that these elevations are completely ablated by the introduction of rapamycin. This is in full support of the notion that mTOR is required for muscle cell differentiation and demonstrates that GSI-mediated myogenesis enhancement is dependent on mTOR. In contrast, we demonstrated that GSI treatment protects MPS and myotube size in differentiated C2C12s exposed to rapamycin, suggesting that GSI may modulate MPS in an mTOR-independent manner.

Given AKT's ability to regulate myotube differentiation and elevate protein synthesis independent of mTOR through regulation of GSK3 $\beta$, myotubes were also exposed to the AKT inhibitor, API-1 [26,40,41]. In a similar fashion, API-1 diminished GSI-mediated enhancements on $\mathrm{C} 2 \mathrm{C} 12$ differentiation, which is in concert with prior findings that AKT is essential for the initiation of myoblast differentiation [41]. However, API-1 alone was not sufficient to reduce mTOR or MPS in differentiated myotubes. API- 1 is a novel small molecule inhibitor that has gained research attention in recent years as a possible anticancer therapeutic, and, while evidence shows reduced pAKTSer473, to our knowledge it is unclear if both pAKTThr308 and Ser473 are reduced with API-1 treatment [31,42-44]. Here, we show that API-1 only reduced pAKTSer473 and not pAKTThr308. This may explain why we did not observe detectable reductions in mTOR signaling or MPS with API-1 treatment. Though it is reported that reductions in AKT can blunt protein synthesis, other proteins may influence mTOR independent of AKT, which could explain why the use of API-1 is not sufficient enough to reduce protein synthesis [6,7,45]. In contrast, API-1 treatment did reduce another downstream target of AKT, pGSK3 $\beta$ Ser9 and subsequent ABC protein expression, demonstrating that the use of API-1 does negatively influence the AKT function. Furthermore, despite its lack of effect on MPS, API-1 treatment did reduce myotube size. AKT is a known pro-survival signaling pathway and API-1 has 
shown to induce apoptosis, thus the atrophy observed in the present study is likely due to heighted protein breakdown and not a suppression of MPS [46-48]. However, we did not measure specific indices of protein catabolism in the present study and can only speculate at this time.

An underlying premise of this study was to gain better insight into the mechanisms by with GSI treatment elevates MPS in C2C12 myotubes, and since API-1 alone was not sufficient to reduce protein synthesis, myotubes were exposed to API-1 and RAP together. Intriguingly, GSI treatment was able to rescue protein synthesis rate and myotube size in the presence of both API-1 and RAP, suggesting that GSI may mediate MPS in a mechanism independent of AKT/mTOR. Our data suggests that this rescue of MPS may be via GSK3 $\beta$. When active, GSK3 $\beta$ phosphorylates and inactivates the translation initiation factor eIF2B [28,40]. However, when GSK3 $\beta$ is phosphorylated on Ser9 by AKT, eIF2B is able to partake in translation initiation [49]. As mentioned above, pGSK3 $\beta$ Ser9 was significantly reduced with API-1 treatment. Interestingly, pGSK3 $\beta$ Ser9 was rescued with GSI treatment in the presence of API-1, suggesting that GSIs may act on GSK3 $\beta$ independent of AKT. In concert with this finding, ABC was also rescued, indicating that function of GSK3 $\beta$ may be modulated by GSIs independent of AKT. This is not the first time that GSIs or Notch and GSK3 $\beta$ crosstalk have been postulated. In fact, during investigations using HEK293T cells, smooth muscle cells and fibroblasts have identified Notch as a target of GSK3 $\beta$ [50-52]. Interestingly, however, work within skeletal muscle has also suggested a regulatory role of Notch on GSK3 $\beta$. Brack et al. discussed GSK3 $\beta$ as a mediator between Notch and Wnt during skeletal muscle regeneration, demonstrating GSI-mediated elevations in pGSK3 $\beta$ Ser9 similar to our present findings [16]. However, their work did not discuss GSK3 $\beta$ as a mediator of protein synthesis and did not investigate whether GSI treatment impacts MPS. GSK3 $\beta$ is a known regulator of MPS and overexpression of its downstream target eIF2B $\varepsilon$ has shown to significantly increase rates of MPS and induce muscle hypertrophy [40,53]. Additionally, Notch signaling has been implicated in regulating muscle hypertrophy in both in vivo and in vitro models [22,54-56]. To our knowledge, we are the first to address the research paradigm of Notch as a regulator of MPS and have shown for the first time that GSI treatment may modulate MPS independently of mTOR/AKT. An interesting yet puzzling finding from our lab's prior work was that 4EBP1 was the only downstream target of mTOR that was altered in a protein synthesis positive fashion with GSI treatment. This may actually support the idea that GSI-mediated elevations or rescue of MPS is through GSK3 $\beta$. In fact, recent studies within cancer cell lines have implicated GSK3 $\beta$ directly in the phosphorylation of 4EBP1 $[57,58]$. It is also interesting that GSK3 $\beta$ has been implicated in regulating PTEN stabilization $[59,60]$. Based on our previous published work demonstrating alterations in the PTEN/AKT/mTOR cascade, it is plausible that GSI treatment's modulation of PTEN/AKT/mTOR is via GSK3 $\beta$.

Though our present study reveals that GSIs may be able to rescue MPS when combined with mTOR and AKT inhibitors, this study is not without limitations. Though we have validated GSI treatment as a strategy to increase MPS in vitro, whether GSIs augment MPS in vivo requires further investigation. It should be noted that GSI administration did counteract muscle wasting in a setting of cachexia, but in this case MPS was not assessed [22]. Additionally, though GSIs are routinely used to target Notch signaling, they are not specific to Notch, and have several additional target substrates [61,62]. A large majority of $\gamma$-secretase substrates are transmembrane receptors, much like the Notch receptor family, and have known roles within skeletal muscle. For example, the insulin receptor, insulin-like growth factor 1 receptor, and growth hormone receptor, all of which partake in anabolic signaling, have been identified as $\gamma$-secretase substrates [62]. However, to our knowledge, the regulation of these receptors by GSIs have not been investigated specifically within skeletal muscle. Another $\gamma$-secretase substrate, low-density lipoprotein receptor-related protein 6 (LRP6), is a transmembrane receptor crucial to canonical Wnt signaling [62,63]. Crosstalk between Notch and Wnt have been widely discussed for proper skeletal muscle regeneration, while LRP6-mTOR signaling has been investigated in cardiomyocytes 
and hepatocytes $[1,64,65]$. Yet, whether LRP6-mTOR signaling occurs in skeletal muscle or whether LRP6 is responsible for changes in MPS is unknown. Recent work has also demonstrated that inhibition of the receptor for advanced glycation end products (RAGE), a $\gamma$-secretase substrate, can partially protect against age-associated muscle atrophy [66]. Further, a proteomics approach following GSI treatment in chick myogenic cells identified sonic hedgehog (Shh) as one of the most altered signaling pathways. Interestingly, separate studies have shown that Shh promotes myoblast proliferation, while also increasing myoblast fusion $[67,68]$. Yet, to our knowledge, the role of Shh on MPS has not been investigated. Thus, given the vast array of $\gamma$-secretase substrates, future investigations must delineate whether Notch is the specific GSI target that is responsible for alterations in MPS reported in the present study. Lastly, though we have demonstrated that administration of a GSI is able to promote pGSK3 $\beta$ Ser9 in the presence of API-1, and thus are speculating that GSI-mediated rescue of MPS is via GSK3 $\beta$, future work will be required to confirm this mechanism of action.

\section{Conclusions}

This study provided additional validation for the use of GSIs to promote or rescue MPS. We demonstrated that GSI treatment can rescue MPS independently of AKT and $\mathrm{mTOR}$, possibly through regulation of GSK3 $\beta$. These findings warrant further investigation on the role of GSIs in muscle-wasting conditions, in particular instances in which tumorsuppressing drugs (Rapamycin, API-1) are used, or where MPS rates are reduced, as GSIs may elevate MPS and help to sustain skeletal muscle mass.

Supplementary Materials: The following are available online at https:/ / www.mdpi.com/article/ 10.3390/cells10071786/s1, Figure S1: GSI preserves myotube size in the presence of rapamycin, Figure S2: GSI preserves myotube size in the presence of API-1, Figure S3: GSI preserves myotube size in the presence of rapamycin and API-1.

Author Contributions: Conceptualization, J.R.H.; methodology, J.R.H.; software, J.R.H., B.T. and C.M.; formal analysis, J.R.H. and S.T.A.; investigation, J.R.H.; data curation, J.R.H., B.T. and C.M.; writing—original draft preparation, J.R.H.; writing—review and editing, J.R.H., J.S.M., S.T.A.; visualization, J.R.H.; supervision, S.T.A.; project administration, J.R.H.; funding acquisition, S.T.A. All authors have read and agreed to the published version of the manuscript.

Funding: This research received no external funding but was funded through a UNC Charlotte Faculty Research Grant (S.T.A.).

Institutional Review Board Statement: Not applicable.

Informed Consent Statement: Not applicable.

Data Availability Statement: Data sharing is not applicable to this article.

Conflicts of Interest: The authors declare no conflict of interest.

\section{References}

1. Arthur, S.T.; Cooley, I.D. The effect of physiological stimuli on sarcopenia; impact of Notch and Wnt signaling on impaired aged skeletal muscle repair. Int. J. Biol. Sci. 2012, 8, 731-760. [CrossRef] [PubMed]

2. Lexell, J. Human aging, muscle mass, and fiber type composition. J. Gerontol. A Biol. Sci. Med. Sci. 1995, 50, 11-16. [PubMed]

3. Morley, J.E.; Baumgartner, R.N.; Roubenoff, R.; Mayer, J.; Nair, K.S. Sarcopenia. J. Lab. Clin. Med. 2001, 137, 231-243. [CrossRef] [PubMed]

4. Huot, J.R.; Novinger, L.J.; Pin, F.; Narasimhan, A.; Zimmers, T.A.; O'Connell, T.M.; Bonetto, A. Formation of colorectal liver metastases induces musculoskeletal and metabolic abnormalities consistent with exacerbated cachexia. JCI Insight 2020. [CrossRef] [PubMed]

5. Kim, H.G.; Huot, J.R.; Pin, F.; Guo, B.; Bonetto, A.; Nader, G.A. Reduced rDNA transcription diminishes skeletal muscle ribosomal capacity and protein synthesis in cancer cachexia. FASEB J. 2021, 35, e21335. [CrossRef] [PubMed]

6. Laplante, M.; Sabatini, D.M. mTOR signaling in growth control and disease. Cell 2012, 149, 274-293. [CrossRef]

7. Shimobayashi, M.; Hall, M.N. Making new contacts: The mTOR network in metabolism and signalling crosstalk. Nat. Rev. Mol. Cell Biol. 2014, 15, 155-162. [CrossRef] 
8. Antikainen, H.; Driscoll, M.; Haspel, G.; Dobrowolski, R. TOR-mediated regulation of metabolism in aging. Aging Cell 2017, 16, 1219-1233. [CrossRef]

9. Harrison, D.E.; Strong, R.; Sharp, Z.D.; Nelson, J.F.; Astle, C.M.; Flurkey, K.; Nadon, N.L.; Wilkinson, J.E.; Frenkel, K.; Carter, C.S.; et al. Rapamycin fed late in life extends lifespan in genetically heterogeneous mice. Nature 2009, 460, 392-395. [CrossRef]

10. Lamming, D.W.; Ye, L.; Katajisto, P.; Goncalves, M.D.; Saitoh, M.; Stevens, D.M.; Davis, J.G.; Salmon, A.B.; Richardson, A.; Ahima, R.S.; et al. Rapamycin-induced insulin resistance is mediated by mTORC2 loss and uncoupled from longevity. Science 2012, 335, 1638-1643. [CrossRef]

11. Neff, F.; Flores-Dominguez, D.; Ryan, D.P.; Horsch, M.; Schroder, S.; Adler, T.; Afonso, L.C.; Aguilar-Pimentel, J.A.; Becker, L.; Garrett, L.; et al. Rapamycin extends murine lifespan but has limited effects on aging. J. Clin. Investig. 2013, 123, 3272-3291. [CrossRef] [PubMed]

12. Wilkinson, J.E.; Burmeister, L.; Brooks, S.V.; Chan, C.C.; Friedline, S.; Harrison, D.E.; Hejtmancik, J.F.; Nadon, N.; Strong, R.; Wood, L.K.; et al. Rapamycin slows aging in mice. Aging Cell 2012, 11, 675-682. [CrossRef]

13. Johnson, S.C.; Rabinovitch, P.S.; Kaeberlein, M. mTOR is a key modulator of ageing and age-related disease. Nature 2013, 493, 338-345. [CrossRef] [PubMed]

14. Goodman, C.A.; Frey, J.W.; Mabrey, D.M.; Jacobs, B.L.; Lincoln, H.C.; You, J.S.; Hornberger, T.A. The role of skeletal muscle mTOR in the regulation of mechanical load-induced growth. J. Physiol. 2011, 589, 5485-5501. [CrossRef] [PubMed]

15. Willett, M.; Cowan, J.L.; Vlasak, M.; Coldwell, M.J.; Morley, S.J. Inhibition of mammalian target of rapamycin (mTOR) signalling in $\mathrm{C} 2 \mathrm{C} 12$ myoblasts prevents myogenic differentiation without affecting the hyperphosphorylation of 4E-BP1. Cell Signal. 2009, 21, 1504-1512. [CrossRef]

16. Brack, A.S.; Conboy, I.M.; Conboy, M.J.; Shen, J.; Rando, T.A. A temporal switch from notch to Wnt signaling in muscle stem cells is necessary for normal adult myogenesis. Cell Stem Cell 2008, 2, 50-59. [CrossRef]

17. Conboy, I.M.; Conboy, M.J.; Smythe, G.M.; Rando, T.A. Notch-mediated restoration of regenerative potential to aged muscle. Science 2003, 302, 1575-1577. [CrossRef]

18. Carey, K.A.; Farnfield, M.M.; Tarquinio, S.D.; Cameron-Smith, D. Impaired expression of Notch signaling genes in aged human skeletal muscle. J. Gerontol. A Biol. Sci. Med. Sci. 2007, 62, 9-17. [CrossRef]

19. D'Souza, D.M.; Zhou, S.; Rebalka, I.A.; MacDonald, B.; Moradi, J.; Krause, M.P.; Al-Sajee, D.; Punthakee, Z.; Tarnopolsky, M.A.; Hawke, T.J. Decreased Satellite Cell Number and Function in Humans and Mice With Type 1 Diabetes Is the Result of Altered Notch Signaling. Diabetes 2016, 65, 3053-3061. [CrossRef]

20. Jiang, C.; Wen, Y.; Kuroda, K.; Hannon, K.; Rudnicki, M.A.; Kuang, S. Notch signaling deficiency underlies age-dependent depletion of satellite cells in muscular dystrophy. Dis. Models Mech. 2014, 7, 997-1004. [CrossRef]

21. Bi, P.; Kuang, S. Notch signaling as a novel regulator of metabolism. Trends Endocrinol. Metab. 2015, 26, 248-255. [CrossRef]

22. Mu, X.; Agarwal, R.; March, D.; Rothenberg, A.; Voigt, C.; Tebbets, J.; Huard, J.; Weiss, K. Notch Signaling Mediates Skeletal Muscle Atrophy in Cancer Cachexia Caused by Osteosarcoma. Sarcoma 2016, 2016, 3758162. [CrossRef]

23. Pajvani, U.B.; Shawber, C.J.; Samuel, V.T.; Birkenfeld, A.L.; Shulman, G.I.; Kitajewski, J.; Accili, D. Inhibition of Notch signaling ameliorates insulin resistance in a FoxO1-dependent manner. Nat. Med. 2011, 17, 961-967. [CrossRef]

24. Arya, M.A.; Tai, A.K.; Wooten, E.C.; Parkin, C.D.; Kudryavtseva, E.; Huggins, G.S. Notch pathway activation contributes to inhibition of C2C12 myoblast differentiation by ethanol. PLoS ONE 2013, 8, e71632. [CrossRef] [PubMed]

25. Huot, J.R.; Marino, J.S.; Turner, M.J.; Arthur, S.T. Notch Inhibition via GSI Treatment Elevates Protein Synthesis in C2C12 Myotubes. Biology 2020, 9, 115. [CrossRef]

26. Cross, D.A.; Alessi, D.R.; Cohen, P.; Andjelkovich, M.; Hemmings, B.A. Inhibition of glycogen synthase kinase-3 by insulin mediated by protein kinase B. Nature 1995, 378, 785-789. [CrossRef] [PubMed]

27. Glass, D.J. Signalling pathways that mediate skeletal muscle hypertrophy and atrophy. Nat. Cell Biol. 2003, 5, 87-90. [CrossRef]

28. Rommel, C.; Bodine, S.C.; Clarke, B.A.; Rossman, R.; Nunez, L.; Stitt, T.N.; Yancopoulos, G.D.; Glass, D.J. Mediation of IGF-1induced skeletal myotube hypertrophy by PI(3)K/Akt/mTOR and PI(3)K/Akt/GSK3 pathways. Nat. Cell Biol. 2001, 3, 1009-1013. [CrossRef] [PubMed]

29. Li, B.; Ren, H.; Yue, P.; Chen, M.; Khuri, F.R.; Sun, S.Y. The novel Akt inhibitor API-1 induces c-FLIP degradation and synergizes with TRAIL to augment apoptosis independent of Akt inhibition. Cancer Prev. Res. 2012, 5, 612-620. [CrossRef]

30. Yoon, M.S.; Chen, J. Distinct amino acid-sensing mTOR pathways regulate skeletal myogenesis. Mol. Biol. Cell 2013, 24, 3754-3763. [CrossRef]

31. Henning, R.J.; Sanberg, P.; Jimenez, E. Human cord blood stem cell paracrine factors activate the survival protein kinase Akt and inhibit death protein kinases JNK and p38 in injured cardiomyocytes. Cytotherapy 2014, 16, 1158-1168. [CrossRef] [PubMed]

32. Huot, J.R.; Pin, F.; Essex, A.L.; Bonetto, A. MC38 Tumors Induce Musculoskeletal Defects in Colorectal Cancer. Int. J. Mol. Sci. 2021, 22, 1486. [CrossRef] [PubMed]

33. Agley, C.C.; Velloso, C.P.; Lazarus, N.R.; Harridge, S.D. An image analysis method for the precise selection and quantitation of fluorescently labeled cellular constituents: Application to the measurement of human muscle cells in culture. J. Histochem. Cytochem. 2012, 60, 428-438. [CrossRef]

34. Schneider, C.A.; Rasband, W.S.; Eliceiri, K.W. NIH Image to ImageJ: 25 years of image analysis. Nat. Methods 2012, 9, 671-675. [CrossRef] 
35. Goodman, C.A.; Hornberger, T.A. Measuring protein synthesis with SUnSET: A valid alternative to traditional techniques? Exerc. Sport Sci. Rev. 2013, 41, 107-115. [CrossRef]

36. Goodman, C.A.; Mabrey, D.M.; Frey, J.W.; Miu, M.H.; Schmidt, E.K.; Pierre, P.; Hornberger, T.A. Novel insights into the regulation of skeletal muscle protein synthesis as revealed by a new nonradioactive in vivo technique. FASEB J. 2011, 25, 1028-1039. [CrossRef]

37. Ge, Y.; Chen, J. Mammalian target of rapamycin (mTOR) signaling network in skeletal myogenesis. J. Biol. Chem. 2012, 287, 43928-43935. [CrossRef]

38. Jansen, K.M.; Pavlath, G.K. Molecular control of mammalian myoblast fusion. Methods Mol. Biol. 2008, 475, 115-133. [CrossRef]

39. Park, I.H.; Chen, J. Mammalian target of rapamycin (mTOR) signaling is required for a late-stage fusion process during skeletal myotube maturation. J. Biol. Chem. 2005, 280, 32009-32017. [CrossRef] [PubMed]

40. Jefferson, L.S.; Fabian, J.R.; Kimball, S.R. Glycogen synthase kinase-3 is the predominant insulin-regulated eukaryotic initiation factor 2B kinase in skeletal muscle. Int. J. Biochem. Cell Biol. 1999, 31, 191-200. [CrossRef]

41. Wilson, E.M.; Rotwein, P. Selective control of skeletal muscle differentiation by Akt1. J. Biol. Chem. 2007, 282, 5106-5110. [CrossRef] [PubMed]

42. Jin, H.; Sanberg, P.R.; Henning, R.J. Human umbilical cord blood mononuclear cell-conditioned media inhibits hypoxic-induced apoptosis in human coronary artery endothelial cells and cardiac myocytes by activation of the survival protein Akt. Cell Transplant. 2013, 22, 1637-1650. [CrossRef] [PubMed]

43. Karaboga Arslan, A.K.; Yerer, M.B. alpha-Chaconine and alpha-Solanine Inhibit RL95-2 Endometrium Cancer Cell Proliferation by Reducing Expression of Akt (Ser473) and ERalpha (Ser167). Nutrients 2018, 10, 672. [CrossRef] [PubMed]

44. Saglam, A.S.; Alp, E.; Elmazoglu, Z.; Menevse, E.S. Effect of API-1 and FR180204 on cell proliferation and apoptosis in human DLD-1 and LoVo colorectal cancer cells. Oncol. Lett. 2016, 12, 2463-2474. [CrossRef]

45. Mirzoev, T.M.; Tyganov, S.A.; Shenkman, B.S. Akt-dependent and Akt-independent pathways are involved in protein synthesis activation during reloading of disused soleus muscle. Muscle Nerve 2017, 55, 393-399. [CrossRef] [PubMed]

46. Brunet, A.; Bonni, A.; Zigmond, M.J.; Lin, M.Z.; Juo, P.; Hu, L.S.; Anderson, M.J.; Arden, K.C.; Blenis, J.; Greenberg, M.E. Akt promotes cell survival by phosphorylating and inhibiting a Forkhead transcription factor. Cell 1999, 96, 857-868. [CrossRef]

47. Waldemer-Streyer, R.J.; Chen, J. Myocyte-derived Tnfsf14 is a survival factor necessary for myoblast differentiation and skeletal muscle regeneration. Cell Death Dis. 2015, 6, e2026. [CrossRef] [PubMed]

48. Ren, H.; Koo, J.; Guan, B.; Yue, P.; Deng, X.; Chen, M.; Khuri, F.R.; Sun, S.Y. The E3 ubiquitin ligases beta-TrCP and FBXW7 cooperatively mediates GSK3-dependent Mcl-1 degradation induced by the Akt inhibitor API-1, resulting in apoptosis. Mol. Cancer 2013, 12, 146. [CrossRef]

49. Gordon, B.S.; Kelleher, A.R.; Kimball, S.R. Regulation of muscle protein synthesis and the effects of catabolic states. Int. J. Biochem. Cell Biol. 2013, 45, 2147-2157. [CrossRef]

50. Espinosa, L.; Ingles-Esteve, J.; Aguilera, C.; Bigas, A. Phosphorylation by glycogen synthase kinase-3 beta down-regulates Notch activity, a link for Notch and Wnt pathways. J. Biol. Chem. 2003, 278, 32227-32235. [CrossRef]

51. Foltz, D.R.; Santiago, M.C.; Berechid, B.E.; Nye, J.S. Glycogen synthase kinase-3beta modulates notch signaling and stability. Curr. Biol. 2002, 12, 1006-1011. [CrossRef]

52. Guha, S.; Cullen, J.P.; Morrow, D.; Colombo, A.; Lally, C.; Walls, D.; Redmond, E.M.; Cahill, P.A. Glycogen synthase kinase 3 beta positively regulates Notch signaling in vascular smooth muscle cells: Role in cell proliferation and survival. Basic Res. Cardiol. 2011, 106, 773-785. [CrossRef]

53. Mayhew, D.L.; Hornberger, T.A.; Lincoln, H.C.; Bamman, M.M. Eukaryotic initiation factor 2B epsilon induces cap-dependent translation and skeletal muscle hypertrophy. J. Physiol. 2011, 589, 3023-3037. [CrossRef]

54. Der Vartanian, A.; Audfray, A.; Al Jaam, B.; Janot, M.; Legardinier, S.; Maftah, A.; Germot, A. Protein O-fucosyltransferase 1 expression impacts myogenic C2C12 cell commitment via the Notch signaling pathway. Mol. Cell. Biol. 2015, 35, 391-405. [CrossRef]

55. Al Jaam, B.; Heu, K.; Pennarubia, F.; Segelle, A.; Magnol, L.; Germot, A.; Legardinier, S.; Blanquet, V.; Maftah, A. Reduced Notch signalling leads to postnatal skeletal muscle hypertrophy in Pofut1cax/cax mice. Open Biol. 2016, 6. [CrossRef]

56. Pelisse, M.; Der Vartanian, A.; Germot, A.; Maftah, A. Protein O-Glucosyltransferase 1 Expression Influences Formation of Differentiated Myotubes in C2C12 Cell Line. DNA Cell Biol. 2018, 37, 359-372. [CrossRef]

57. Ito, H.; Ichiyanagi, O.; Naito, S.; Bilim, V.N.; Tomita, Y.; Kato, T.; Nagaoka, A.; Tsuchiya, N. GSK-3 directly regulates phospho4EBP1 in renal cell carcinoma cell-line: An intrinsic subcellular mechanism for resistance to mTORC1 inhibition. BMC Cancer 2016, 16, 393. [CrossRef]

58. Shin, S.; Wolgamott, L.; Tcherkezian, J.; Vallabhapurapu, S.; Yu, Y.; Roux, P.P.; Yoon, S.O. Glycogen synthase kinase-3beta positively regulates protein synthesis and cell proliferation through the regulation of translation initiation factor $4 \mathrm{E}-\mathrm{binding}$ protein 1. Oncogene 2014, 33, 1690-1699. [CrossRef]

59. Al-Khouri, A.M.; Ma, Y.; Togo, S.H.; Williams, S.; Mustelin, T. Cooperative phosphorylation of the tumor suppressor phosphatase and tensin homologue (PTEN) by casein kinases and glycogen synthase kinase 3beta. J. Biol. Chem. 2005, 280, 35195-35202. [CrossRef] [PubMed]

60. Maccario, H.; Perera, N.M.; Davidson, L.; Downes, C.P.; Leslie, N.R. PTEN is destabilized by phosphorylation on Thr366. Biochem. J. 2007, 405, 439-444. [CrossRef] [PubMed] 
61. Rosa de Andrade, I.; Correa, S.; Fontenele, M.; de Oliveira Teixeira, J.D.; Abdelhay, E.; Costa, M.L.; Mermelstein, C. gammaSecretase Inhibition Induces Muscle Hypertrophy in a Notch-Independent Mechanism. Proteomics 2018, 18. [CrossRef]

62. Haapasalo, A.; Kovacs, D.M. The many substrates of presenilin/gamma-secretase. J. Alzheimers Dis. 2011, 25, 3-28. [CrossRef]

63. Ren, Q.; Chen, J.; Liu, Y. LRP5 and LRP6 in Wnt Signaling: Similarity and Divergence. Front. Cell Dev. Biol. 2021, 9, 670960. [CrossRef]

64. Chen, Z.; Li, Y.; Jiang, G.; Yang, C.; Wang, Y.; Wang, X.; Fang, B.; Zhang, G.; Sun, Y.; Qian, J.; et al. Knockdown of LRP6 activates Drp1 to inhibit survival of cardiomyocytes during glucose deprivation. Biomed. Pharmacother. 2018, 103, 1408-1414. [CrossRef]

65. Li, L.; Xue, J.; Wan, J.; Zhou, Q.; Wang, S.; Zhou, Y.; Zhao, H.; Wang, X. LRP6 Knockdown Ameliorates Insulin Resistance via Modulation of Autophagy by Regulating GSK3beta Signaling in Human LO2 Hepatocytes. Front. Endocrinol. 2019, 10, 73. [CrossRef]

66. Davis, H.M.; Essex, A.L.; Valdez, S.; Deosthale, P.J.; Aref, M.W.; Allen, M.R.; Bonetto, A.; Plotkin, L.I. Short-term pharmacologic RAGE inhibition differentially affects bone and skeletal muscle in middle-aged mice. Bone 2019, 124, 89-102. [CrossRef] [PubMed]

67. Ma, L.; Li, C.; Lian, S.; Xu, B.; Yuan, J.; Lu, J.; Yang, H.; Guo, J.; Ji, H. ActivinA activates Notch1-Shh signaling to regulate proliferation in C2C12 skeletal muscle cells. Mol. Cell. Endocrinol. 2021, 519, 111055. [CrossRef] [PubMed]

68. Teixeira, J.D.; de Andrade Rosa, I.; Brito, J.; Maia de Souza, Y.R.; Paulo de Abreu Manso, P.; Machado, M.P.; Costa, M.L.; Mermelstein, C. Sonic Hedgehog signaling and Gli-1 during embryonic chick myogenesis. Biochem. Biophys. Res. Commun. 2018, 507, 496-502. [CrossRef] [PubMed] 